\title{
Direitos humanos, gênero e patriarcado: o estupro como ato-violação
}

ISSN: 2358-0844

n. II, v. 2 mai. -out. 2019 p. 126-141.

\author{
Luana Lima ${ }^{1}$ \\ Laura dos Santos Boeira²
}

RESUMO: As sociedades contemporâneas parecem ter como marca comum os atravessamentos das estruturas de gênero delineadas por estruturas de poder. O estupro evidencia, sob a égide do patriarcado, diversas facetas do uso abusivo dos corpos femininos e feminilizados. Objetiva-se debater a temática do estupro de corpos femininos através das intersecções entre gênero e direitos humanos. Nesse sentido, foi realizada uma pesquisa crítica de revisão de literatura alicerçado nos saberes supracitados. No ato-violação do estupro, a masculinidade e o poder se entrelaçam. $\mathrm{O}$ uso do aparelhamento sexual parece responder às necessidades não sexuais; são atos orientados por condutas moralistas, de dominação e posse. O corpo da mulher é expropriado no estupro cruento como formas de: 1) punição contra uma mulher genérica que saiu da sua posição de subordinada dentro de um sistema de relações; 2) como agressão ou afronta contra um homem também genérico; 3) como uma demonstração de virilidade para uma comunidade de pares. No contexto intrafamiliar, como direito por quem, como provedor, exige pagamento do débito das mulheres do seu grupo. No âmbito legal, parece haver uma distinção significativa entre o estupro cruento - mais facilmente reconhecido pela sociedade como crime por se tratar de um autor desconhecido - e o estupro por parceiro íntimo ou familiar, no qual encontramos discursos que mais protegem a família enquanto instituição do que a mulher como sujeito de direitos. A influência do estatuto do autor e, especialmente, da vítima, a relação entre eles, o histórico de moralidade e sexualidade determinam o acesso ou não aos procedimentos de direito, como a punibilidade, abortamento, etc. No âmbito do acesso à saúde, o aborto por estupro permanece tendo estatuto de crime, a despeito das legislações, com a punição sendo aplicada informalmente pelos profissionais de saúde, mediada por seus preceitos morais. Destarte, o despreparo e falta de capacitação das equipes, a discriminação, o estigma, a moralidade, etc., desembocam na reprodução da violência contra a mulher, numa máquina que vai do lar ao Estado, gerida pelo patriarcado.

PALAVRAS-CHAVE: Estupro; Direitos Humanos; Patriarcado; Gênero.

\begin{abstract}
Contemporary societies seem to have as a common mark the crossings of gender structures and structures of power. Rape, operating under the patriarchy, shows us different sides of the abusive use of feminine and feminized bodies. This essay aims to discuss the issue of rape of women through the intersections between gender and human rights. We conducted a literature review to retrieve articles that debated this subject and analyzed those critically. Through the act of rape, masculinity and power intertwine. This sexual act responds to non-sexual needs; they are guided by moralistic conduct, domination and possession. The woman's body is taken in a rape as form of: 1) punishment against a generic woman who has left her subordinate position within a system of relationships; 2) as an aggression or affront against a man, also generic; 3) as a demonstration of virility to a community of peers.
\end{abstract}

${ }^{1}$ Mestra em bioética pela Universidade de Brasília (UnB), psicóloga e bacharel interdisciplinar em humanidades pela Universidade Federal da Bahia (UFBA). E-mail: luanalima.sc@outlook.com

${ }_{2}^{2}$ Mestra em bioética (UnB) e psicóloga pela Universidade Federal do Rio Grande do Sul (UFRGS). E-mail: boeira.lb@gmail.com 
In the domestic context, it is considered as a right by whom, as a "provider", demands payment of the debt from the women of his group. In the legal sphere, there seems to be a significant distinction between the rape that happens in the streets - more easily recognized by society as a crime because it is an unknown perpetrator - and the rape by a family member or intimate partner, where the discourses seek to protect the family as an institution more than consider the woman as subject of rights. The access to procedures of law (punishment for the rapist) and health (abortion) by the women seem to depend on who the rape's perpetrator was, who she, as a victim, is, what was the relationship between them and the history of morality and sexuality in that context. Concerning the access to health, abortion after a rape remains a crime, regardless of legislation, with punishment being applied informally by health professionals, mediated by their moral standards. Thus, the unpreparedness of the health teams, the discrimination, the stigma, the morality, etc., leads to the reproduction of violence against women, in a machine that goes from home to the government, managed by patriarchy.

Keywords: Rape; Human Rights; Patriarchy; Gender.

ISSN: 2358-0844

п. II, v. 2 mai. -out. 2019 p. 126-141.

Resumen: Las sociedades contemporáneas parecen tener como marca común los atravesamientos de las estructuras de género delineadas por estructuras de poder. La violación evidencia, bajo la égida del patriarcado, diversas facetas del uso abusivo de los cuerpos femeninos y feminilizados. En ese trabajo, se pretende debatir la temática de la violación de cuerpos femeninos a través de las intersecciones entre género y derechos humanos. Se realizó una investigación crítica de revisión de literatura basada en los saberes arriba citados. En el acto-violación del estupro, la masculinidad y el poder se entrelazan. El uso del aparato sexual parece responder a necesidades no sexuales; son actos orientados por conductas moralistas, de dominación y posesión. El cuerpo de la mujer es expropiado en la violación cruel como formas de: 1) castigo contra una mujer genérica que salió de su posición de subordinada dentro de un sistema de relaciones; 2) como agresión o afrenta contra un hombre también genérico; 3) como una demostración de virilidad para una comunidad de pares. En el contexto intrafamiliar, la violación es comprendida como derecho por quien, como proveedor, exige el pago del débito de las mujeres de su grupo. En el marco legal, parece haber una distinción significativa entre la violación que ocorre em las calles - más fácilmente reconocida por la sociedad como crimen por tratarse de un autor desconocido - y la violación por um hombre íntimo o familiar, donde encontramos discursos que más protegen a la familia como institución, que la mujer como sujeto de derechos. La influencia del estatuto del autor y, especialmente, de la víctima, la relación entre ellos, el histórico de moralidad y sexualidad determinan el acceso o no a los procedimientos de derecho, como la punibilidad, el aborto, etc. En el ámbito del acceso a la salud, el aborto por violación sigue teniendo estatuto de crimen, a pesar de las legislaciones, con el castigo siendo aplicado informalmente por los profesionales de salud, mediado por sus preceptos morales. La despreparación y falta de capacitación de los equipos, la discriminación, el estigma, la moralidad, etc., desembocan en la reproducción de la violencia contra la mujer, en una máquina que va del hogar al Estado, gestionada por el patriarcado.

Palabras clave: Violación; Derechos Humanos; Patriarcado; Género.

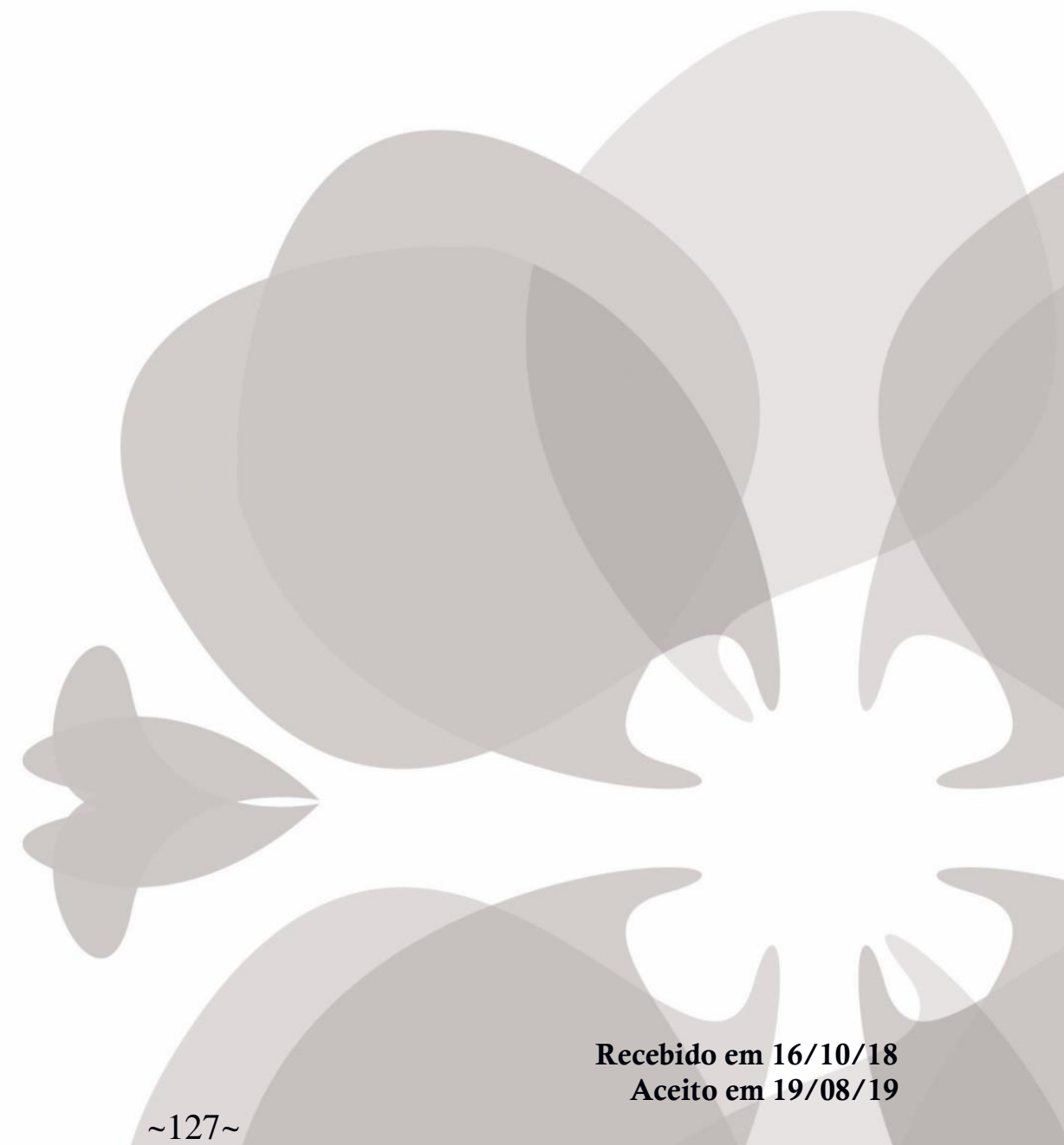


Os âmbitos acadêmico e militante unem esforços para pensar e lutar por direitos humanos considerando a relevância do relativismo cultural. Apesar do respeito pela diversidade, historicamente, as sociedades parecem ter como marca comum os atravessamentos das estruturas de gênero delineadas por estruturas de poder. Rita Laura Segato (2011, p. 24) destaca a importante função das relações de gênero, ao passo que afirma a necessidade de resistência às vigentes roupagens de violência, de novos e cruéis modos de vitimização dos corpos femininos e feminizados. O estupro é um fenômeno que evidencia, sob a égide do patriarcado, diversas facetas do uso abusivo dos corpos femininos.

Talvez o primeiro passo nessa caminhada seja o reconhecimento, conforme propõe Hannah Arendt (2007, p. 68), da cisão que adotamos entre a vida pública e a vida privada, intimamente ligada com a compreensão de que política e família seriam instituições distintas, e que a primeira teria muito pouco a opinar sobre as coisas que ocorrem na intimidade do lar. Contudo, com a emergência de uma esfera social-relacional, a linha que separa essas dimensões da vida se torna flexível e até difusa e, rapidamente, começamos a observar um movimento no qual os valores cultivados no núcleo familiar tradicional passam a ditar caminhos para políticas públicas, oferecendo, inclusive, um balizador moral de comportamentos aceitáveis e inaceitáveis. Da mesma forma, os consensos da vida pública operam ultrapassando os limites da porta fechada de casa, causando tensões diversas, notadamente aos grandes proprietários de riquezas ou privilégios, que carregam o receio de sucumbir à condição mediana ou medíocre dos demais membros desse simulacro de comunidade.

Na busca por se afirmar enquanto detentor desse lugar privilegiado, o homem é quem reivindica para si a imagem e semelhança de toda criatura humana. Há um caráter androcêntrico da constituição social que representa um importante viés na forma como esse homem genérico se transforma no ponto de partida de tudo que agenciamos enquanto sujeitos sociais. Nesse sentido, quando pensamos numa abordagem universal dos direitos humanos, por exemplo, o sujeito invisível dessa universalidade parece ser o homem-cidadão-de-direitos - e cada outra pessoa, com características e necessidades diferentes, será pensada e valorada em comparação a ele.

Algumas abordagens feministas atentam para o fato de que esse "universal masculino" inscreve seus parâmetros em corpos reais (RAWLINSON, 2001, p. 407), ou, ainda, como aborda Paul B. Preciado (2002, p. 22), há uma tecnologia social heteronormativa que se apresenta em instituições linguísticas, médicas ou domésticas e se inscreve nos corpos, produzindo sujeitos distintos aos olhos do Estado. Os processos de socialização que esculpem essas identidades sociais condicionam também os padrões de comportamento considerados admissíveis para cada sexo, faixa etária e classe social, etc., 
configurando a estrutura social e produzindo verdades consideradas universais sobre as possibilidades de exercício de cada sujeito no mundo (GUILHEM; AZEVEDO, 2008, p. 231).

Se o Estado-Nação surge, em boa parte, sustentado e sustentando o capitalismo, a razão que permeia seus discursos também partilha a manutenção de uma soberania sobre os corpos, os saberes e as possibilidades de ser do outro. Em sua palestra sobre o tema, Segato (2016) propõe ainda outra palavra para esse processo: donidade (e seus pares: lordship/senhorio). Esse corpo-território, que conquisto e civilizo sob minhas insígnias - que possuo! -, passa a representar objeto-mercadoria, o qual posso, como dono, vender, lucrar, emprestar, violar, quebrar ou matar.

O corpo, compreendido como fato concreto, é um reflexo da incorporação da estrutura social e também um vetor de reprodução e perpetuação da dominação (MONTAGNER, 2008, p. 1591). É a partir da corporeidade que inserimos os sujeitos no mundo e esse corpo, que conta história, também é o corpo-objeto das intervenções que visam a docilizá-lo. O corpo é inscrito pela e é escritor da estrutura social. Podemos pensar a corporeidade como analisador das dimensões da vivência humana social, entendendo o corpo como tela de inscrição das experiências de dor e prazer, sofrimento e reconhecimento (PORTO; GARRAFA, 2005, p. 115). Dora Porto e Volnei Garrafa (2005, p. 116) apontam que afirmar esse estatuto é reconhecer: a) o substrato a partir do qual as culturas desenham as suas diferenças; b) contemplar as sensações de dor e prazer como marcadores somáticos autorregulados que projetam a satisfação das necessidades de sujeitos concretos; c) que provocar prazer ou dor a outros é a base das relações de poder. É sob esse terceiro vetor que nos debruçaremos no presente trabalho.

Debruçar-se sobre o tema do estupro implica uma vinculação a perspectivas do estudo de gênero e da colonialidade, uma vez que, nesse ato-violação, a masculinidade e o poder se entrelaçam. Na opinião de Segato (1999, p. 4) é necessária a indagação dos fantasmas da masculinidade, os quais autorizam os homens a se vincularem de modo radical à violência e à violação de direitos. Ao (re)tecer o sentido e as posições do homem e da mulher na sociedade, poderíamos simular um mundo em que uma mulher livre não fosse sinônimo de ameaça, onde companheiros não impusessem às mulheres condições e/ou demandas com fim de pertencimento e onde as mulheres deixassem de ser entendidas como extensão da sua posse e/ou honra. É uma indagação que também perpassa o questionamento sobre os sentidos de ser mulher na sociedade atual e quais as diferenças entre esse grupo genérico que chamamos de "humanos", que parecem marcar o efetivo acesso a direitos.

É importante destacar que os estudos de gênero têm se ampliado para romper com o binarismo homem-mulher e acolher as diversas formas de identificação e de performatividade de gênero. A 
incidência de estupros cometidos contra a população transexual e travesti no Brasil é alarmante e exige urgente atenção. Todavia, sob o risco sempre presente de não abordar de forma adequada as singularidades e complexidades dos distintos modos de ser no mundo, para fins deste artigo, adotamos o recorte do estupro perpetrado contra a mulher cisgênera.

\section{Direitos humanos e os papéis sociais da mulher}

O primeiro documento da Declaração Universal de Direitos Humanos, publicada logo após a Segunda Guerra Mundial, em 1948, pela Organização das Nações Unidas, traz, em seu artigo 1: “Todos os seres humanos nascem livres e iguais em dignidade e direitos. Dotados de razão e de consciência, devem agir uns para com os outros em espírito de fraternidade.” (ONU, 1948, p. 02).

Em um mundo pós-guerras, pode-se imaginar a relevância da afirmação de valores como a liberdade, a igualdade e a fraternidade, todavia não parece haver espaço para um debate mais aprofundado sobre o lugar social que cada grupo de seres humanos ocupa e os diferentes pontos de partida rumo à igualdade. Ao pressupor que todos nascem iguais, a Declaração exime-se de abordar as demais insígnias sob as quais cada sujeito nasce no mundo: ora, será mesmo igual nascer homem ou mulher nesse mundo? Talvez por reconhecer, historicamente, que as mulheres foram submetidas a diversas restrições de liberdade, inclusive de tomar decisões sobre a própria vida, que, no artigo $16^{\circ}$, a Declaração traz:

1. A partir da idade núbil, o homem e a mulher têm o direito de casar e constituir família, sem restrição alguma de raça, nacionalidade ou religião. Durante o casamento e na altura da sua dissolução, ambos têm direitos iguais.

2. O casamento não pode ser celebrado sem o livre e pleno consentimento dos futuros esposos. (ONU, 1948, p. 04)

O casamento forçado é um dos possíveis analisadores para a temática do estupro vivenciada por mulheres e meninas ao longo dos anos. É de uma violência notável que o reconhecimento do pleno consentimento para o casamento tenha sido afirmado, em nível mundial, apenas na década de 50. Até hoje, essas práticas seguem recorrentes e naturalizadas em diferentes contextos culturais e sociais. Em 1993, quando ocorreu a Conferência Mundial dos Direitos Humanos, em Viena, produziu-se uma nova Declaração, a qual aborda especificamente os direitos humanos das mulheres e das meninas, explicitamente descritos no artigo $18^{\circ}$ :

Os direitos humanos das mulheres e das crianças do sexo feminino constituem uma parte 
inalienável, integral e indivisível dos Direitos Humanos e constituem parte integrante e indivisível dos direitos humanos universais. A participação plena das mulheres, em condições de igualdade, na vida políticas, civil, econômica, social e cultural [...], bem como a erradicação de todas as formas de discriminação com base no sexo, constituem objetivos prioritários da comunidade internacional (OAS, 1993, p. 05)

Ademais, a Declaração de Viena traz destaque especial aos esforços para eliminação de todas as situações de violência baseada no sexo, incluindo diferentes formas de assédio e de exploração sexual. Silvia Pimentel, Ana Lucia Schritzmeyer e Valéria Pandjiarjian (1998, p. 60) indicam que, antes e após a Conferência de Viena, ocorreram outros eventos respaldados pela ONU de afirmação dos direitos das mulheres, tais como a chamada Década da Mulher, entre 1975 e 1985, e a IV Conferência Mundial sobre a Mulher, realizada em Beijing, em 1995. Especificamente sobre a temática do estupro, as autoras ressaltam a Convenção Interamericana para Prevenir, Punir e Erradicar a Violência contra a Mulher, realizada em 1994, em Belém do Pará, pela Organização dos Estados Americanos.

Ao trazer como violência contra a mulher qualquer ato ou conduta baseada no gênero que cause à mulher danos ou sofrimentos físicos, sexuais ou psicológicos, e ressaltar que os mesmos podem ocorrer nas esferas pública ou privada, a Convenção inaugura um novo olhar sobre esse fenômeno (PIMENTEL; SCHRITZMEYER; PANDJIARJIAN, 1998, p. 60). Permite tanto o questionamento acerca de práticas vivenciadas no âmbito familiar e doméstico quanto a responsabilização por parte do Estado quando este omite ou perpetra violências. Karen Giffin (1994, p. 150) aponta para o papel da aliança entre as instituições Estado e família, em que o marido assume direitos legais sobre sua esposa, inclusive podendo controlá-la através de violência física.

Existe uma interpretação etnográfica no contexto intrafamiliar e/ou conjugal do ato violento, especialmente o sexual, como um "direito" por quem tem controle e domínio e, por quem, como provedor, exige um pagamento do débito das mulheres do seu grupo (MACHADO, 2000, p. 317). A radicalidade desse paradigma pode ser reconhecida nos dados que explicitam o feminicídio: metade das mulheres assassinadas no Brasil foram mortas por seus cônjuges atuais ou anteriores - número que acompanha a tendência dos índices mundiais (SEGATO, 2003, p. 7). Dados mais recentes estimam que mais de $75 \%$ dos casos de feminicídio no Brasil foram perpetrados por conhecidos das mulheres, com o feminicídio atingindo estimativas de causa de morte de 5,86 a cada 100 mil mulheres no país (GARCIA et al., 2015, p. 253). 
A tendência de proteger a unidade familiar e não a violentada denuncia a cumplicidade punitiva e o controle patriarcal. Nas palavras de Andrade (2004, p. 99), há um "profundo continuum entre o controle familiar e o penal: não existe uma instância que faça a assepsia, todas se contaminam”. O ciclo de violência reproduzido pelas instituições traz à tona a permissividade do Estado e da ordem social frente à violência contra a mulher no âmbito doméstico:

Uma ordem social de tradição patriarcal por muito tempo "consentiu" num certo padrão de violência contra mulheres, designando ao homem o papel "ativo" na relação social e sexual entre os sexos, ao mesmo tempo em que restringiu a sexualidade feminina à passividade e à reprodução. Com o domínio econômico do homem enquanto provedor, a dependência financeira feminina parecia explicar a aceitação de seus "deveres conjugais", que incluíram o "serviço sexual”. (DANTAS-BERGER; GIFFIN, 2005, p. 418)

Em 1995, na $4^{\text {a }}$ Conferência Mundial sobre a Mulher, há um reconhecimento explícito do estupro dentro do casamento com gravidade equiparada a qualquer outro ato de violência contra a mulher (UN, 1996, p. 38).

\section{Facetas do estupro: entre o desconhecido e o familiar}

Em contraste com o modelo psicopatológico, este trabalho visa questionar a moralidade por um prisma feminista, apostando que o patriarcado desencadeia no aprendizado do estupro (SCULLY apud SEGATO, 1999).

O estatuto de violência entre pessoas desconhecidas é nomeado como estupro cruento:

Aquele perpetrado no anonimato das ruas, por pessoas desconhecidas, anônimas, e no qual a persuasão joga o papel menor, sendo a força ou a ameaça de uso de força o meio pelo qual o ato é realizado. Trata-se do tipo de estupro que, com mais facilidade, aos olhos do cidadão comum e pouco advertido sobre as questões de género, se enquadra na categoria de crime. (SEGATO, 1999, p. 01)

No trabalho de Machado (2000, p. 307), há um traço em comum no discurso dos homens que cometeram o estupro cruento: o reconhecimento da mulher como uma figura de prostituta. Nas entrelinhas dessa afirmação está o entendimento do próprio ato como função contra os costumes morais. Segundo Segato (2016), o violador é o sujeito mais moral de todos. No seu ato de violação está moralizando a vítima, por crer que a mulher merece isso - ideia vislumbrada em uma fala do trabalho de campo de Machado (2000, p. 307): "Ela também errou. Ela vagabundava a altas horas". A 
"reparação" masculina é veiculada pela apropriação do corpo da mulher.

Ampliando a perspectiva masculina acerca do estupro, Segato (1999, p. 09) realizou entrevistas com homens encarcerados que cometeram estupro cruento. $\mathrm{O}$ primeiro dado enigmático da pesquisa diz respeito ao fato desses réus não terem inteiramente evidente que estavam cometendo um crime dado interpretado pela autora como uma face perversa da sobrevivência de um sistema pré-moderno, em que a dominação do corpo feminino, dentro de determinadas condições, não constitui um crime.

Ao ser referido na pesquisa supracitada, o estupro cruento foi triplamente alicerçado: 1. Como punição ou vingança contra uma mulher genérica que saiu do seu lugar, da sua posição subordinada/tutelada dentro de um sistema de status. 2. Como agressão ou afronta contra outro homem também genérico. 3. Como uma demonstração de força e virilidade para uma comunidade de pares.

Segato (1999, p. 09) explora essas categorias subsidiada pela compreensão de que, no primeiro caso, o homem "reage" frente a signos contrários à soberania masculina. A título de exemplo, modos de sociabilidade em que a sexualidade feminina é autonomamente gerida ou, ainda, quando uma mulher se encontra fisicamente longe da proteção ativa de outro homem. A agressão diz respeito a um modo de "desempoderar uma mulher que aos seus olhos lhe pareceu empoderada e desafiadora das hierarquias de poder [...] O intuito [...] é principalmente [...] minar a sua potência e a sua capacidade de subverter as estruturas arcaicas do poder patriarcal” (CAMPOS, 2016, p.09). A posição feminina, reconhecida como uma espécie de rompimento do pré-estabelecido, desafia a posição do homem em uma dualidade relacional dentro de um sistema de relações. Destarte, o ato se apresenta como disciplinador, vingador contra essa mulher genérica. Essa classificação dialoga com o dado de Machado (2000, p. 307), que aponta o olhar masculino sobre a mulher que desafia um sistema de valores como prostituta - uma nomenclatura adjacente que tenta justificar e subverter o crime.

A segunda categoria diz respeito aos casos em que um homem usurpa do corpo de uma mulher para falar para outro homem genérico, cujo poder é desafiado e seu patrimônio roubado em um movimento de reparação. A guerra de poder tem como mediação o corpo feminino, que incorpora uma linguagem para outrem. A terceira explicação para a violência corresponde à demonstração/amostração de competência sexual e força física. Nessa categoria se encaixam os estupros coletivos ou mesmo os crimes solitários dirigidos a alguém à uma comunidade de interlocutores masculinos que lhes supõem um status viril. Esses são, atualmente, alimentados pela cultural da espetacularização, como o caso do Rio de Janeiro, em que vídeos foram intensamente propagados nas redes sociais com teor discursivo e imagético de contemplação da masculinidade. 
Todos os raciocínios supracitados são regulados pelo patriarcado.

Na concepção de Machado (2000, p. 332), a estrutura que alicerça o ato do estupro e sua moralidade se aproxima do significado da perversão na clínica psicanalítica. Não sob a ótica dos homens constituídos sob uma estrutura perversa, mas com investimentos subjetivos semelhantes às atuações dos mesmos. A atuação do perverso reflete transgressões à lei, desafiando-a juntamente à violação do desejo do outro - seu ponto de gozo e satisfação. As construções históricas, sociais e simbólicas de gênero se desdobram em uma cultura sexual perversa em que o masculino se confunde com o lugar da lei. Desse modo é possível notar a

construção social da configuração culturalmente perversa das relações de gênero no imaginário erótico e no imaginário de poder. As fantasias da passividade feminina em torno da ideia unilateral de que o corpo feminino é o apoderado, e o masculino é o ativo, predestinado a servir e a ser apoderado, e que o corpo masculino é o predestinado a apoderar e a se servir do corpo feminino, são os eixos ordenadores do erotismo ocidental. Tais eixos de sentido não só produzem fantasias, mas práticas. O jogo perverso entre os gêneros no imaginário do erotismo, mais do que um jogo de perversos, organiza-se como configuração cultural perversa. (MACHADO, 2000, p.333)

Autoras como Segato (2003), Andrade (2004) e Campos (2016) defendem que a violência não é um meio da satisfação sexual, é um uso da sexualidade para exercício e sustentação da violência estrutural. "Ele é um comportamento sexual a serviço de necessidades não sexuais" (ANDRADE, 2004, p. 96). Isso porque, como defende Campos (2016, p. 09), se a sua intenção fosse de satisfazer um desejo sexual, poderia fazê-lo via sedução, mas na sedução há possibilidade da escusa feminina. Escusar-se é exercer poder. "A prática do estupro [...] é utilizada como um método de controle e de manutenção da hegemonia desse poder patriarcal em todas as suas esferas" (CAMPOS, 2016, p. 07).

As teorias aqui adotadas negam vivamente o argumento do estupro como uma ação decorrente de um desejo sexual ou de adoecimento mental. Ambas as hipóteses referidas têm como base a redução do ato ao aparelhamento biológico - perspectiva que nega a estrutura de gênero delineada pela estrutura de poder, restringindo, por consequência, as possibilidades de políticas de enfrentamento do fenômeno.

No momento em que o domínio da ética e da politica é substituído e reduzido ao campo do biológico, do corpo-espécie, nossos sofrimentos individuais e cotidianos, nossos vínculos sociais, medos e desejos passarão a estar mediatizados por intervenções terapêuticas ou preventivas, sejam elas medicas ou psiquiátricas, interessadas em classificar todos os assuntos próprios da condição humana em termos de normalidade ou patologia, limitando cada vez mais 
A ação política no campo intrafamiliar é ainda mais restrita. Num estudo acerca do perfil dos casos de violência denunciados em uma Delegacia Especializada de Atendimento às Mulheres, no município de Rio Grande/RS, Acosta, Gomes e Barlem (2013, p. 552) verificaram que, nos casos de estupro, o número daqueles perpetrados por desconhecidos era menor do que por parceiros íntimos ou conhecidos. Dado corroborado por Machado (2000, p. 297), em Brasília. A Delegacia Especializada da Mulher do Distrito Federal (DEAM/DF) registrou, na década passada, abundantes denúncias de agressão sexual. Do contingente total, cerca de $60 \%$ dos casos corresponderam à agressores conhecidos. Para a autora, essa modalidade de abuso sofre contrariedades de registro, entre outros motivos, porque acusações que envolvem relações parentais, inclusive matrimoniais, são dificilmente entendidas como estupro pelos processos investigativos e judiciários.

Dantas-Berger e Grifin (2005, p. 422) entrevistaram mulheres e identificaram que, nas relações conjugais, as relações sexuais cedidas ou realizadas sob resistência da mulher eram recorrentes, mas raramente nomeadas pelas mulheres como violência. A modalidade de violência supracitada é problemática por falta de reconhecimento do ato como uma agressão: o homem não se reconhece como agressor, a mulher tem dificuldade de se identificar como vítima e as instituições tendem a não validar esse tipo de denúncia.

A questão da denúncia ou não da violência doméstica contorna um lugar próprio da constituição de subjetividades que se encontram numa posição de tensão entre o privado e o público, entre o antigo e o moderno, entre a barbárie e a política, entre a heteronomia e a autonomia. (TIMM; PEREIRA; GONTIJO, 2011, p.252)

Ocorre que, a despeito dessas relações não serem aparentemente entendidas como violência, elementos desse contato se assemelham às marcas do estupro cruento, como nojo da relação, lavagem/limpeza imediata, pouco desejo sexual, risco de infecções sexualmente transmissíveis, bem como de gravidez indesejada (DANTAS-BERGER; GRIFIN, 2005, p. 423). Dentre os efeitos da violência baseada em questões de gênero, o relatório de Heise (1994) traz consequências tanto para a saúde física - como doenças sexualmente transmissíveis, dores de cabeça, machucados em geral e problemas ginecológicos, entre outros - quanto para a saúde mental. No âmbito da saúde mental, evidencia-se uma tendência ao abuso de substâncias após a violência, manifestações de estresse, depressão, ansiedade, adoção de práticas de automutilação e de exposição a riscos. Em alguns casos, a vivência violenta pode levar as mulheres ao suicídio ou a cometer homicídios. 


\section{A dupla negação do direito ao corpo livre: estupro e instituições}

A questão moral sustenta não apenas os argumentos etnográficos anteriormente explorados, como: a) discursos do senso comum, que frequentemente culpabilizam a vítima pelo ato de violência sofrido; b) leis que regulam o aborto; c) práticas de profissionais que operacionalizam essas leis; d) todas as outras instâncias responsáveis por garantir o direito das mulheres; etc.

No que tange à lei do aborto, esta corresponde ao Decreto Lei nº 2.848 de 07/12/1940. O Art.124 afirma que "provocar aborto em si mesma ou consentir que outrem lhe provoque" concerne à pena/detenção de um a três anos. As exceções atuais da lei equivalem apenas a três situações com o consentimento da mulher: quando há risco de vida da gestante, casos de malformação fetal com inviabilidade de vida extrauterina e gravidez resultante de estupro.

De acordo com Débora Diniz et al (2014, p. 292), ao passo que a exceção punitiva se esboça como um sopro de soberania das mulheres sobre o seu próprio corpo, denuncia uma discussão sobre a moralidade: a construção da mulher como vítima. Quando há risco de vida, a mulher é vítima da doença; quando ela sofre um estupro, da violência oriunda do patriarcado; no caso de anencefalia/má formação fetal, do acaso da natureza. Nesse sentido, os avanços da lei não expressam ou protegem a autonomia das mulheres, mas a proteção corresponde à mulher-vítima.

A autoridade médica delineia os diagnósticos de má formação fetal, bem como risco de vida da mulher. Nos casos de estupro, a quem cabe a descrição de uma mulher como vítima? A ela mesma? A polícia e seus regimes investigativos? Os laudos médicos? O silêncio deixado pelo Código Penal sobre como estabelecer a verdade do estupro foi respondido por um dos últimos documentos produzidos pelo Ministério da Saúde, que representa algum avanço em direção ao direito das mulheres (DINIZ et. al, 2014, p. 292): a Norma Técnica de Prevenção e Tratamento dos Agravos Resultantes da Violência Sexual Contra Mulheres e Adolescentes.

Essa Norma Técnica estabeleceu a palavra da mulher como suficiente para acesso ao aborto legal, ao passo que mulher violentada sexualmente não tem o dever legal de noticiar o fato à polícia. Deve-se orientá-la a tomar as providências policiais e judiciais cabíveis, mas, caso ela não o faça, não lhe pode ser negado o abortamento. Esse documento ainda normatizou os procedimentos para o atendimento ao abortamento em gravidez por violência sexual, contemplou a organização da atenção, bem como a construção de um guia geral para esse atendimento.

Periódicus, Salvador, n.11, v. 2, mai-out.2019 - Revista de estudos indisciplinares em gêneros e sexualidades Publicação periódica vinculada ao Núcleo de Pesquisa NuCuS, da Universidade Federal da Bahia - UFBA ISSN: 2358-0844 - Endereço: http://www.portalseer.ufba.br/index.php/revistaperiodicus 
O Estado entrega com uma mão aquilo que já retirou com a outra: cria uma lei que defende as mulheres da violência à qual estão expostas porque esse mesmo Estado já destruiu as instituições e o tecido comunitário que as protegia. O advento moderno tenta desenvolver e introduzir seu próprio antídoto para o veneno que inocula. (SEGATO, 2014, p.04)

Apesar do avanço legislativo, os conjuntos de normas atuais parecem não corresponder ou dar conta da realidade. Uma pesquisa qualitativa, coordenada por Débora Diniz (DINIZ et. al, 2014), realizada com 82 profissionais de saúde que atuam em serviços de aborto previsto em lei, em cinco capitais do Brasil, buscou compreender o itinerário a que a mulher é submetida, notadamente pela via da construção da verdade do estupro. Nesse estudo, constatou-se a existência de uma dimensão moral que antecede e acompanha a mulher no serviço: o aborto por estupro permanece tendo estatuto de crime, mas sem punição. Nesse sentido, o trabalho dos profissionais é atravessado por uma questão sustentada por um teor de ambiguidade legal: seriam os serviços essenciais de proteção às necessidades de saúde das mulheres ou serviços liminares à moral criminalizadora?

Em função desse embate, pela economia moral sobre o corpo e a sexualidade das mulheres que rejeitam à heteronomia reprodutiva imposta às mesmas, bem como pela sobreposição de regimes institucionais - serviços precisam justificar seus procedimentos, quando preciso, ao Ministério Público, há uma vigilância expressa por práticas pericias nas rotinas organizacionais dos serviços. A tecnologia do inquérito parece ter sido incorporada aos saberes e práticas biomédicas por via dos testes de verdade. Há confrontação de relatos e datas via repetição de depoimentos, nexo causal - acontecimento da violência e se este é a causa da gravidez-, leitura sobre a subjetividade da vítima, etc. O comportamento, o choro e a consternação são analisados, de forma que o trauma se delineia como categoria moral para a efetivação dos direitos (DINIZ et al, 2014, p. 296).

O território da cena de estupro é um dos moduladores para o teste de verdade, bem como o autor da violência. Se o estupro é cruento, maiores as chances de a mulher estar falando a verdade. Se a violência ocorreu dentro de casa, as pessoas têm dificuldade de reconhecer o evento na vida conjugal, de forma a identificar a narrativa como suspeita - dado que converge o argumento defendido por Segato (1999, p. 05) e Machado (2000, p. 299), que afirmam que o estupro intrafamiliar sofre dificuldades de enquadramento e aceitação social, desde o âmbito jurídico. Por outro lado, se a violência entre conhecidos tiver como vítima uma criança, o estupro parece mover práticas de compaixão (DINIZ et al., 2014, p. 295).

A realidade evidenciada nas instituições de saúde parece convergir com os desafios 
encontrados nas instituições jurídicas. Pimentel, Schritzmeyer e Pandjiarjian (1998, p. 63) analisaram, dentre outros fatores, a postura que o Poder Judiciário continua reproduzindo, acriticamente, de estereótipos e preconceitos sociais, inclusive de gênero, o que impede a efetivação da igualdade calcada em princípios de solidariedade, equidade e justiça. Andrade (2004, p. 81) delata a lógica da seletividade do sistema, afirmando a desvalorização do fato-crime cometido em prol da investigação sobre as pessoas envolvidas (autor e vítima), de acordo com os estereótipos. Em outras palavras, apesar de não haver previsão legal, o julgamento de um crime sexual corresponde ao julgamento simultâneo e confrontado, numa relação de forças, do autor e da vítima: status familiar, comportamento, vida pregressa, reputação sexual, etc.

A análise supracitada é denominada pelo autor de "lógica da honestidade", que demarca e explicita, principalmente, o posicionamento feminino. Ou seja, uma linha divisória entre as mulheres consideradas honestas (do ponto de vista da moral sexual dominante), que podem ser consideradas vítimas pelo sistema, e as mulheres desonestas - prostitutas como modelo radicalizado -, que o sistema abandona na medida em que não se adequam aos protótipos de moralidade sexual impostos às mulheres.

A própria palavra da vítima então está a se exigir que sua palavra seja corroborada por sua vida pregressa, por sua moral sexual ilibada, por seu recato e pudor. Existindo ou não laudo pericial, ou ainda prova testemunhal, mesmo em situações de flagrante delito, a palavra da vítima perde credibilidade se não for ela considerada "mulher honesta". (ANDRADE, 2004, p.93)

O risco em questão corresponde não apenas à negação de direitos das mulheres estereotipadas como "desonestas", como numa inversão da vitimização, podendo ser as mulheres acusadas pelas alegações de consentimento, provocação ou prazer no ato violento, especialmente se o autor não corresponder ao estereótipo de estuprador. A "hermenêutica da suspeita" no inquérito policial e no processo penal, igualmente vislumbrada nas instituições de saúde, deriva em duas outras adversidades graves: a impunidade e o descrédito da denúncia, que não apenas violenta a mulher, como pode, com alguma margem, transformá-la em ré.

O primeiro aspecto é trabalhado por Andrade (2005, p. 94), que afirma que ser considerada vítima nos "labirintos da honestidade" não implica necessariamente na punibilidade do autor. Pelo contrário, os dados trazidos pelo autor revelam que o Sistema de Justiça Criminal absolve com mais frequência do que condena. Paralelamente, reforçando a impunidade, vislumbra-se mecanismos de responsabilização da mulher sobre os fatos. No mês de abril de 2017, aconteceu uma consulta pública no Portal e-Cidadania acerca de uma tramitação na Comissão de Direitos Humanos do 
Senado Federal, uma Sugestão Legislativa 7/2017, que pretende tornar crime hediondo e inafiançável a "falsa acusação de estupro". Uma proposta que legitima a tendência de retirar o foco do criminoso e a culpabilizar a vítima.

\section{Considerações finais}

O estupro enquanto ato violento e violador representa a égide do patriarcado. A partir de leituras etnográficas e institucionais, o presente trabalho problematizou o fenômeno via desconstrução da ideia do estupro como oriundo do desejo sexual ou adoecimento psíquico, ao passo em que avançou na defesa do ato como produto da violência estrutural.

Disposições de gênero, especialmente no que tange à corporeidade feminina, são delineadas por estruturas de poder. Essa afirmação pode ser reconhecida na constituição familiar, que esboça, historicamente, a separação entre os âmbitos público e privado. Essa fragmentação institucional autoriza/autorizou não apenas ocorrências violentas sem critério na “intimidade do lar”, potencializando a vulnerabilidade feminina, como também semeou uma política baseada na concepção estereotipada de quem seriam os estupradores e quem seriam as vítimas. De modo a delinear avaliações pouco objetivas, preponderam critérios e elementos outros, como a vitimização - termo que abarca raciocínio e práticas normativas -, o trauma, credibilidade em função do status ou vida sexual da vítima e do autor da violência, bem como da relação entre eles, aspectos que validam os casos de estupro cruento e questionam os casos intrafamiliares/conjugais.

A noção supracitada, que sustenta não apenas o senso comum, como as ações institucionais, determinam o acesso ao cuidado, tratamento, legitimidade da denúncia, prosseguimento do processo à penalidade do crime. Ainda que a lei, os Direitos Humanos, o papel social da mulher, etc., tenham sofrido avanços importantes, os dados da realidade no país apontam para precarização do sistema. O sistema brasileiro, seja no âmbito da saúde, no sistema jurídico ou penal, se delineou por processos de seletividade e moralidade no acesso e proteção à direitos às mulheres vítimas de estupro, desconsiderando, muitas vezes, a noção da agressão como resultante da economia simbólica da masculinidade. Destarte, o despreparo ou falta de capacitação das equipes, a discriminação, o estigma, a moralidade, etc., desembocam na reprodução da violência, uma máquina de vai do lar ao Estado, gerida pelo patriarcado. 


\section{Referências}

ACOSTA, Danielle Ferreira; GOMES, Vera Lúcia de Oliveira.; BARLEM, Edison Luiz Devos. Perfil das ocorrências policiais de violência contra a mulher. Acta Paul Enferm, São Paulo, v. 26, n. 6, p. 547-53, dez 2013.

ANDRADE, Vera Regina. A soberania patriarcal: o sistema de justiça criminal no tratamento da violência sexual contra a mulher. Revista Sequencia, n.50, p.71-102, 2005.

ARENDT, Hannah. A condição humana. 10.ed. Rio de Janeiro: Forense Universitária, 2007.

CAMPOS, Andrea Almeida. A cultura do estupro como método perverso de controle nas sociedades patriarcais. Revista Espaço Acadêmico, v. 16, n. 183, ago 2016.

CAPONI, Sandra. Biopolítica: entre as ciências da vida e a gestão das populações. In: GARRAFA, Volnei; PORTO, Dora; MARTINS, Gerson Zafalon; BARBOSA, Swendenberg do Nascimento. Bioética, poderes e injustiças - 10 anos depois. Brasília: CFM/Catedra Unesco de Bioetica/ SBB, 2012.

DANTAS-BERGER, Sônia Maria; GIFFIN, Karen. A violência nas relações de conjugalidade: invisibilidade e banalização da violência sexual? Cad. Saúde Pública, Rio de Janeiro, v. 21, n. 2, p. 417-425, mar/abr, 2005.

DINIZ, Débora; DIOS, Vanessa; MASTRELLA, Miryam; MADEIRO, Alberto. A verdade do estupro nos serviços de aborto legal no Brasil. Rev. Bioética [online], vol.22, n.2, p. 291298, 2014.

GARCIA, Leila Posenato; FREITAS, Lucia Rolim Santana de; SILVA, Gabriela Drummond Marques da; HÖFELMANN; Doroteia Aparecida. Estimativas corrigidas de feminicídios no Brasil, 2009 a 2011. Rev Panam Salud Publica, v. 37, n. 4/5, p. 251-257, 2015.

GIFFIN, Karen. Violência de gênero, sexualidade e saúde. Cad. Saúde Pública, Rio de Janeiro, v. 10, supl. 1, p. 146-155, 1994.

GUILHEM, Dirce; AZEVEDO, Anamaria Ferreira. Bioética e gênero: moralidades e vulnerabilidade feminina no contexto da Aids. Revista Bioética, v. 16, n. 02, p. 229-40, 2008.

HEISE, Lori. Violence Against Women: The Hidden Health Burden. In: World Bank Discussion Papers 255, Washington, D.C, World Bank, 1994. Disponível em: http://documents.worldbank.org/curated/pt/489381468740165817/Violence-againstwomen-the-hidden-health-burden - Acesso em 23 de agosto de 2017.

MACHADO, Lia Zanotta. Sexo, estupro e purificação. In: SUÁREZ M, BANDEIRA L, organizadores. Violência, gênero e crime no Distrito Federal. Brasília: Paralelo 15/Editora UnB; 1999. p. 297-352.

MONTAGNER, Miguel Ângelo. Pierre Bourdieu e a saúde: uma sociologia em Actes de la Recherche em Sciences Sociales. Cadernos de Saúde Pública, Rio de Janeiro, v. 24, n. 7, p.15881598, jul 2008.

PIMENTEL, Silvia; SCHRITZMEYER, Ana Lucia; PANDJIARJIAN, Valeria. Estupro: direitos humanos, gênero e justiça. Revista USP, v. 37, n. 1, p. 58-69, 1998.

PRECIADO, Paul B. Manifiesto contra-sexual. Madrid: Opera Prima, 2002.

PORTO, Dora; GARRAFA, Volnei. Bioética de intervenção: considerações sobre a economia do mercado. Revista Bioética, v. 13, n.1, 2005.

RAWLINSON, Mary. The concept of a feminist bioethics. Journal of Medicine and Philosophy, v. 26, n. 4 , p. 405-416, 2001.

SEGATO, Rita Laura. A estrutura de gênero e a injunção do estupro. In: SUARÉZ, Mireya; BANDEIRA, Lourdes (orgs). Violência, gênero e crime no Distrito Federal. Brasília: Paralelo 15 e UnB, 1999.

SEGATO, Rita. Laura. Las estructuras elementales de la violencia: contrato y estatus en la etiología de la violência. In: SEGATO, Rita Laura. Las estructuras elementales de la violência. 1. ed. Bernal: Universidad Nacional de Quilmes, 2003.

Periódicus, Salvador, n.11, v. 2, mai-out.2019 - Revista de estudos indisciplinares em gêneros e sexualidades Publicação periódica vinculada ao Núcleo de Pesquisa NuCuS, da Universidade Federal da Bahia - UFBA ISSN: 2358-0844 - Endereço: http://www.portalseer.ufba.br/index.php/revistaperiodicus 
SEGATO, Rita Laura. Género y colonialidad: en buscas de claves de lectura y de un vocabulario estratégico descolonial. In: BIDASECA, Karina; VAZQUEZ LABA, Vanesa. (Eds.). Feminismos y poscolonialidad. Buenos Aires: Ed. Godot, 2011.

SEGATO, Rita Laura. 10 anos da Declaração Universal sobre Bioética e Direitos Humanos - DUBDH. In: III Jornada de Bioética do Distrito Federal: Dignidade Humana em Debate. Brasília: 2016. PALESTRA

TIMM, Flávia; PEREIRA, Ondina; GONTIJO; Daniela. Psicologia, violência contra mulheres e feminismo: em defesa de uma clínica política. Psicologia Política, v. 11. N. 22, p. 247-259, jul-dez 2011.

UNITED NATIONS (UN). Report of the Fourth World Conference on Women. New York, 1996. Disponível em: http://www.un.org/womenwatch/daw/beijing/fwcwn.html Acesso em 13 de julho de 2017. 